\title{
Exploring Factors Influencing the Success of Crowdfunding Campaigns of Startups in Vietnam
}

\author{
Associtated Professor Tran Thi Thanh $\mathrm{Tu}^{1}$, Dinh Phuong $\mathrm{Anh}^{1} \&$ Tang Thi Ha Thu ${ }^{1}$ \\ ${ }^{1}$ VNU-UEB \\ Correspondence: Associtated Professor Tran Thi Thanh Tu, VNU-UEB
}

Received: December 7, 2017

Accepted: December 26, 2017

Online Published: January 4, 2018

doi:10.5430/afr.v7n2p19

URL: https://doi.org/10.5430/afr.v7n2p19

\begin{abstract}
Over the past years, crowdfunding has been known as an effective funding channel for startups, especially in developed countries such as the United States, the United Kingdom and Germany. Nowadays, along with the rise of startups in Vietnam, will crowdfunding be a fruitful funding channel? What are the success determinants for a crowdfunding campaign of startups in Vietnam? With the data from five most well-known crowdfunding platforms (CFP) in Vietnam, we explore the factors which are significant for the success of crowdfunding campaigns of startups. Besides, this article also shed lights on the prospects and challenges ofcrowdfunding in Vietnam and proposes some recommendations for parties participating in the crowdfundingsystem.
\end{abstract}

Keywords: Crowdfunding, Startup

\section{Introduction}

In recent years, crowdfunding (CF) has emerged as an effective funding channel for startups and new ventures besides traditional channels such as venture capital or angel investors. Questions about CF have been examinedby a large number of researchers. Among those questions, the volume of affectionof various factors to the success of a CF campaign is one of the most concerning topics which various researchers had conducted studies all over the world. Some of the most cited studies on this topic are Mollick (2014) which examined factors such as target capital, duration, number of videos and images with the data from 48.526 crowdfunding projects on kickstarter.com; Ahler et al. (2015), examined the affection of information of project owners, numbers of funders and investors taking part in CF campaign and number of comments; Koch and Siering(2015) evaluated the influences of capital distribution in the business plan of each project and risk information.

However, until now we have not found any research that sufficiently assembles factors affecting successes of CF campaigns. In recent years, even though CF is used to seek finance for new ventures in Viet Nam, it is still in its infancy. With the growingof startups in Vietnam, many law drafts have been proposed, in which CF is considered as an official funding channel for small and medium enterprises, especially startups in Vietnam. This can be seen as a positive signal of the parallel development of startups and CF in Vietnam in the coming years. However, CF is still a new concept, so far we have not found any research on CF in Vietnam.

The paper aims at exploring and examining factors which influence the success of CF campaigns of Vietnamese startups using the data from five most well-known crowdfunding platforms in Vietnam. After the introduction, the second part focuses on literature review on crowdfunding, the third part proposed methodology and data collection, the research results and disccusions are presented in the forth part and the final part suggests some recommendations and conclusions to increase the effectiveness of crowdfunding practicein Vietnam.

\section{Literature review and Overview on Crowdfunding}

Crowdfunding though has been considered as an effective funding channel for new ventures in many parts of the world, the literature on crowdfunding is quite novel and embryonic.

Within recent years, more and more scholars are making efforts on studying various aspects of CF. One of the first works to introduce the general concept for this innovative funding channel is Belleflamme et al. (2010), they state: the concept of CF has its roots in crowdsourcing, which refers to using the crowd to obtain knowledge, ideas, feedback and effective solutions to develop a company or organization.According to them "Crowdfunding involves an open call, essentially through the Internet, for the provision of financial resources either in form of donation or in 
exchange for some form of reward and/or voting rights."Schwienbacher and Larralde (2010) stated that crowdfunding was a direct call for funding, in which project owners seek financial help directly from the general public instead of indirectly through financial intermediaries. However, nowadays there are more and more Crowdfunding Platforms (CFP) which act as intermediaries between entrepreneurs seeking capital and public investors, such as Fundable, Kickstarter, Kiva, SellaBrand (Schwienbacher and Larralde, 2010; Belleflamme et al., 2010). Hemer (2011) explained that it is reasonable and crucial for a CFP to function as an intermediary because CFP is more experienced andprofessional in crowdfunding than both investors and project owners.

As CF is an innovative funding channel which is still in its infancy, it is necessary to study various aspects of CF. Legal issues related to CF have been analyzed by Bradford (2014). The author considers the cost and benefits of CF and "proposes an exemption that would free CF from the registration requirements of federal securities law". Valencience and Jegeleviciute (2013) take a look at CF through the SWOT analysis in order to obtain a comprehensive picture of the subject with strengths and weaknesses and also identify the opportunities and challenges facing this innovative funding channel. Pazowski and Czudec (2014) uncover and expands knowledge on economic conditions for the application of CF.

Additionally, several studies calculate the affection of various factors to the funding success in CF campaigns. Agrawal et al. (2010), examining the data on Sella Band platform, show that crowdfunding projects are mostly financed by local investors, thus they suggest a positive impact of localized social capital on the success of crowdfunding campaigns. Schwienbacher and Larralde (2012) focus on an equity-based individually startup and suggest that building a community of crowdfunders who enjoy additional utility from their participation is necessary for crowdfunding success. Mollick (2014) also examines the relation between geography and the success of crowdfunding projects, using a dataset of over 48.500 projects on Kickstarter platform. The author reveals "a strong geographic component to the nature of projects, with founders proposing projects that reflect the underlying cultural products of their geographic area." Mollick also suggests that personal network of the projects' owners and the quality of the projects themselves are associated with the success of CF campaigns. Furthermore, Koch and Siering (2015) apply media richness theory in crowdfunding context to examine 199.441 CF projects on Kickstarter.com and find that different communication cues affect the crowdfunding success.

Currently, more and more studies focus on investigating factors influencing the success of crowdfunding projects. However, until now we have not found any research that sufficiently assembles factors affecting the success of CF campaigns. Additionally, though the trend of seeking capital for startups through CF is becoming more popular in Vietnam, we have not found any published research on CF in Vietnam. Additionally, even though the trend of seeking capital for startups through CF is becoming more popular in Vietnam, so far we have not found any major publications on $\mathrm{CF}$ in Vietnam. In order to fill this research gap, we conduct this study: "Exploring factors influencing the success of crowdfunding campaigns for startups in Vietnam".

\subsection{Key Features of Crowdfunding}

Until now, there is no most comprehensive answer to the question "What is crowdfunding?". Therefore, after examining a variety of definitions we summarize and outline the key features of $\mathrm{CF}$ as below:

(1) Crowdfunders and backers are individuals, they may or may not be sophisticated investors. Crowdfunders do not only fund the ventures but also give ideas, provide feedback, market information and solutions to develop products or services.

(2) The financial value of each contribution from crowdfunders is relatively small. The more funders participate in a project, the greateramount of capital the project owner will raiseand the more likely that the $\mathrm{CF}$ campaign will be successful.

(3) The benefits thatcrowdfunders will receive can be rewards, specific rights and/or an amount of money. In the case of donation-based crowdfunding, funders do not require any benefit and right when they support the project.

(4) Every CF campaign is conducted on crowdfunding platforms through the Internet. The Internet makes it easier for the funders to obtain information on the project and the project owner before they make decision. In addition, this is alsoa salient feature of CF compared to other funding methods because it eliminates geographic constraints between funders all over the world and the project

\subsection{The Financing Process of Crowdfunding}

There are three major parties in a crowdfunding process: Project initiator, funder and aonline crowdfunding platform 
(CFP).

The financing process starts when the project initiator makes an application with a business plan and required information on a CFP. After passing the screening phase set out by platform providers, selected projects will be announced on CFP and begin to receive pledges from crowdfunders. At the end of crowdfunding period, if the project achieves the target amount of capital, the project owner will receive the full amount of money raised; conversely, if the target amount is not reached, all of the raised funds will be reimbursed to the contributors and the CF campaign will be considered unsuccessful.

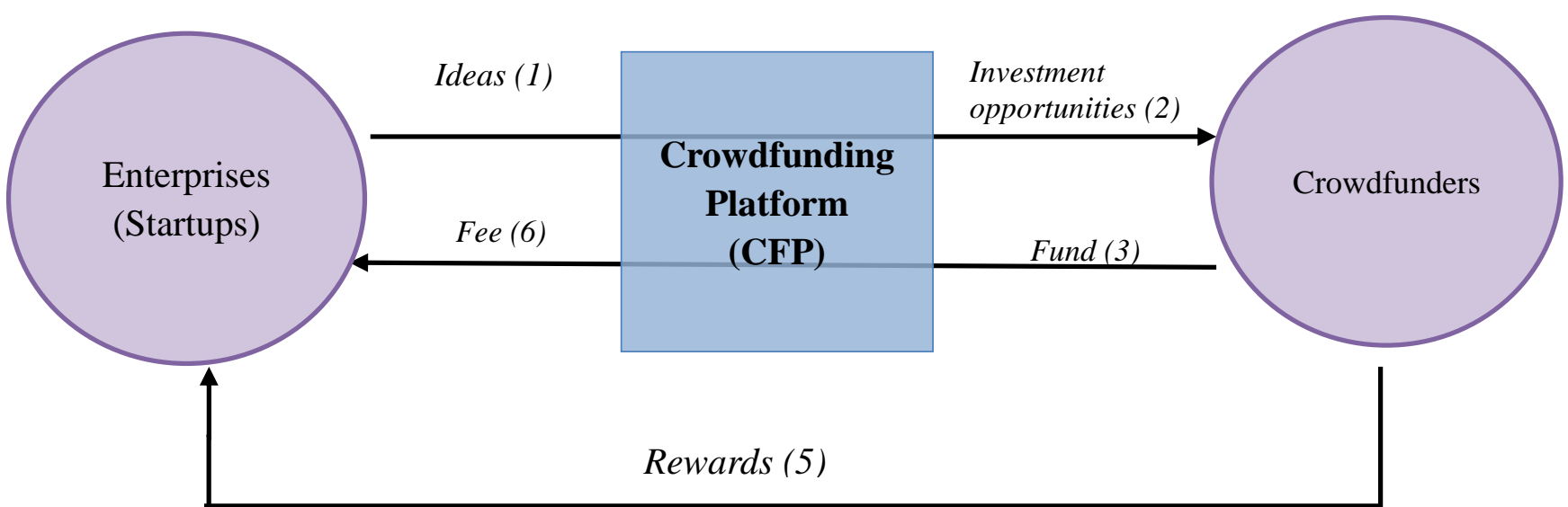

Figure 1. Crowdfunding process

Source: Assembled from Hemer (2011); Valanciene and Jegeleviciute (2014);

Hagedorn and Pinkwart (2015).

\section{Data and Methodology}

\subsection{Variables}

Table 1. Summary of variables and hypotheses

\begin{tabular}{llll}
\hline No. & Factor & Variables & Hypothetical impact \\
\hline 1 & Project information & Project info & Positive \\
2 & Risk information & Risk info & Positive \\
3 & Picture & Picture & Positive \\
4 & Video & Video & Positive \\
5 & Update & Update & Positive \\
6 & Comment & Comment & Positive \\
7 & Email & Email & Positive \\
8 & Facebook & Facebook & Positive \\
9 & Phone number & Phone & Positive \\
10 & Founder info & Teaminfo & Positive \\
11 & Duration & Duration & Negative \\
12 & Goal & Goal & Negative \\
13 & Funding level & No of reward level & Positive \\
14 & Backer & No of backer & Positive \\
\hline
\end{tabular}

\section{Source: Sumarrize by the authors}

\section{Dependent variables}

Dependent variables predict the status of project - success or failure. Five most well-known crowdfunding platforms in Vietnam follow the "all or nothing" or threshold model, which means funders' pledge money is only collected if the target capital amount is reached. In other words, a CF campaign will only be successful if the amount of money raised is higher or equal to the goal set by the project initiatorbefore launching the CF campaign; projects 
that have the total amount of money raised lower than the goal is considered as a failed campaign. In our research, the status of the CF campaign can get one of two values: either 0 or 1 . The value is 1 when the project is successful and 0 when it is a failed campaign.

\section{Independent variables}

Project information (information about how project founder distribute and use raised capital in their project): Information describes the project on the crowdfunding platform has significant impact on crowdfunder's awareness (Mudamb and Schuff, 2010); the more detailed the description, the more useful it is for the funder's decision (Cheung et al, 2008). When project founder uploadsspecific information onaccounting or how raised money is used in the project, the project becomesmore transparent and attractive to crowdfunders. Therefore, it helps to build trust and encourages people to give comment and feedback about the product (or service) and share their idea on how to use the capital effectively.

Risk information (include commitment): One of the most crucial information people often consider before making investment decision is the risk of a project. Thus, risk information of a project is a significant factor which influences the success of a CF campaign (Koch and Siering, 2015). Information about the project's risk can be made public in the profile of the project. By doing this, it helps people to learn more about the project before making their decisions. Koch and Siering (2015) stated that the information about risk could be seen as an advantage because the crowdfunders could "join hand" with the project founder to solve problems and lower the risk. In addition, making the risk information public also help project founders to build trust with crowdfunders by showing that the project is not some type of online fraud. This will also encourage people to invest in the project and engage in the CF campaign.

Picture: Pictures often attract more attention from people than words do (Glenberg and Langston, 1992), information delivered through pictures get into our mind more quickly and have a much higher percentage of recall than normal document (Unnava and Burnkrant, 1991). Danaher et al (2006) also proved that charts, pictures, photographs have a significant impact on the number of viewers on a website and the durationof their visit. Pictures can motivate people to "click" and see the project. In other words, using pictures to promote a project can attract more attention from people and also make it easier for funders to share to their family and friends, potentially attracts more investors.

Video: Besides documents and pictures, the project founder can use videos to present the idea about the project. they help to deliver the message to people through their eyes, their ears, and their brains, they help people to receive and remember information more effectively. Some crowdfunding project (for profit or non-profit) with a specific category such as arts, film, music..., videos can be the key factor of success as they help project founders to attract funders' attention and encourage people to "put money into their project". In the case that project have information representedin type of documents, videos and pictures, more people will choose to watch video first (whether they read the word descriptionor not) then if they have interest and eager to learn more about the project, they will continue to read the document and look at the pictures. If the project does not have any video, people may not be eager to search and learn more about it (no matter how great the potential of the project is) (Koch and Siering, 2015).

Update: After having carried out the project for a while, crowdfunders do not only care about the quality and potential of the project but also the total number of funders as well as the total amount of money raised at that time. If the project founder often updates the status of the project, new funders will have more evidence to convince themselves that the project is worth investing (Koch and Siering, 2015). Xu et al (2014) proved that the project that usually updates their information in Kickstarter.com and indiegogo.com had a higher percentage of success than others. However, Kuppuswamy and Bayus (2013) have a different standpoint. These authors stated that by updating project information, the project founder and crowdfunders will feel that the duration of the CF campaign is coming more closer. Thus, it can have impact in two different ways: in a positive way, it will push potential funders to make their investment decisions more quickly and this will lead to a situation in which the project can be overfunded before the CF campaign ends; however, in a negative way, this will givethe project founder more pressure to raise enough money before the CF campaign ends and in the worse situation, this also makes funders hesitant to invest in a project that is approaching the deadline. Both Giudici et al (2013) and Mollick (2014) proved that updating information can have a direct impact on the success of crowdfunding project.

Comment: the number of comments shows the engagement of crowdfunders in the project and also improves the interaction between the funders and the founder,it helps funders learn more about the project and cooperate with the founder to develop the product. (Antonento et al, 2014). 
Facebook (Project's Facebook): Crowdfunders can get project information through project's Facebook page besides project's profile in crowdfunding platform website. Lin et al (2013) stated that information about contributions, choices and interactions between founder and people is one of the factors leading to success. These information aremade accessibleon theproject's Facebook pagethrough the comments, the number of likes and sharesfrom the people who may or may not have invested in the project.

Email: Funders can also ask project founder about specific information, but sometimes, they have to do it privately to prevent conflicts. For that reason, the email of the founder or the project is needed. Email can be another helpful way for the founder and funders to communicate with each other. It helps backers learn more about the project and allows project founder to provide more information about the project or even ask for help.

Phone (founder's phone number): In order to make communication easierfor funders and project initiator, especially in emergency cases or fraud, it is necessary for the founders to upload their phone number. Uploading cell phone number in project's profile can be an effective way for the founder to build trust with the funders.

Founder information: To persuade people to invest in theproject, it is necessary for the founder to introduce himself/herselfin a way that is enough to convince potential funders that he and/or his team will use the amount of raised capital in the most efficient way. Wheat et al (2013) suggestedthat project founder information uploaded on $\mathrm{CF}$ campaign profile can establish the connection between thefounder and the funders, helps people to understand the story of each project, the original idea as well as the mission they want to accomplish. Ahler et al (2015), Leboeuy and Schwienbacher (2015), Colombo et al (2015), Moysido and Spaeth (2016) proved that by uploading founder information, it could directly influence the success of a project.

Duration: The amount of time in which the project carries out its CF campaign to raise fund. Burtch et al (2013) pointed out that the longer a project is launched, the more opportunities it has to receive capital and the higher probability of success. On the home page of Kickstarter.com, it says that projects those are carried out in a longer time are more likely to reach the goal than others, some of them have incredible results. However, Mollick (2014) and Muller et al. (2013) showed a different standpoint, whichargued that the length of duration did not guarantee that a project could be successful. They stated that duration had a negative impact on a project success. The statistic that Muller et al. (2013) calculatedshowed that many failed CF campaigns were carried out until the expiry day but still did not reach their goals if they did not make enough impression during the first period of the campaigns.

Goal (Project's goal): The amount of capital the project founder seeks to raise through crowdfunding, this fund helpsthe founder to initiatethe project,upgrade and/or develop product or service. However, the goal might be set much higher than what is needed, therefore, it becomes hard to achieve. Mollick (2014), Leboey and Schwienbacher (2015), Ahler et al. (2015), came to a conclusion that the lower the goal, the higher the probability of success the project can achieve but it has to be high enough to cover all the cost of the project.

Funding level: In this paper, the funding levels can be understood as the levelsof reward, which correspond to different amounts of money. Funding level, as well as reward level, is one of the most concerning factors influencing investment decision of funders (Ahler et al., 2015), and it can also work as a marketing leverage if the reward is chosen wisely. (Drablos, 2015).Loboey and Schwienbacher (2015) pointed out if the project had a lot of investment options, funders would have more chance to find the most suitable option to invest in the project.

Backer: The number of funders supporting the project. The more backers a project has, the more likely that it will succeed (Ahler et al, 2015). Molick (2014), Loeoey and Schwienbacher (2015) and Ahler et al. (2015) concluded that the number of backers had a significant impact on a project's success.

\subsection{Data and Methodology}

As an exploratory empirical study, the goal of this research is to explore and evaluate factors influencing the probability of success of crowdfunding campaigns in Vietnam with comparision to existing theories. Therefore, we use not only formal hypothesis testing to evaluate factors but also apply PEST analysis to examine the prospects and challenges of crowdfunding as a new form of fundraising for startups in Vietnam.

The study has 14 independent variables; therefore, the minimum sample size is $14 * 5=70$ samples, equivalent to 70 observations or 70 projects. Besides, the selected observations are projects using $\mathrm{CF}$ to raise fund which have start and end dates within the time frame of the data collection. In order to fulfill the purposes of this study, we manually collectedthe data of 124 projectsfrom five most well-known crowdfunding platform websites in Vietnam: Betado.com, Comicola.com, Firststep.vn, Fundstart.vn, Funding.vn. Each of 124 projects has start and end dates from January 1, 2015 to March 31, 2017. 
The data of 14 variables examined in this study was published online in 124 projects' profiles on CFPs and is still available to access until the research period.Among 124 projects we collected, 62 of them succeededand the other 62 projects failed.124 projects are categorized in 10 different fields: music (6 projects), agriculture (10 projects), games (4 projects), communities ( 8 projects), books (17 projects), trade (35 projects), technology ( 27 projects), art ( 2 projects), health (4 projects), education (11 projects). All projects used reward-based model.The summary of all the collected data can be found in Table 2 .

It can be seen that the sample size of this study is not as large as otherstudies fromregions such as the United States of America, the United Kingdom or China. This is understandable due to the fact that until now CF has been a novel fundraising method in Vietnam and the number of CF campaigns is still low. The first CF projects were carried out in 2013 but did not attract much attention. Until 2014, when CF campaigns for comic books became famous, CFbecame more popular in Vietnam. So far, there have been a small number of Vietnamese startups seeking capital through CF.Therefore, the total number of CF campaigns we couldcollectfrom the five most well-known CFPs listed above is not a large number. At the same time, it should be noticed that all five most well-known CFPs in Vietnam are using the reward-based model for CF projects.

Table 2. Summary statistics

\begin{tabular}{|c|c|c|c|c|c|}
\hline \multirow[t]{2}{*}{ Dependent Variable } & \multirow[t]{2}{*}{ Status } & \multirow[t]{2}{*}{ Mean } & \multirow[t]{2}{*}{ Std. Error } & \multicolumn{2}{|c|}{ 95\% Confidence Interval } \\
\hline & & & & Lower Bound & Upper Bound \\
\hline \multirow{2}{*}{$\%$ Achieve } & 0 & 20.714 & 43.998 & -66.385 & 107.814 \\
\hline & 1 & 345.541 & 44.714 & 257.025 & 434.057 \\
\hline \multirow{2}{*}{ Picture } & 0 & 5.159 & 1.190 & 2.804 & 7.514 \\
\hline & 1 & 20.180 & 1.209 & 17.787 & 22.574 \\
\hline \multirow{2}{*}{ Duration } & 0 & 24.841 & 4.039 & 16.845 & 32.837 \\
\hline & 1 & 37.000 & 4.105 & 28.874 & 45.126 \\
\hline \multirow{2}{*}{ Comment } & 0 & 1.381 & 1.365 & -1.322 & 4.084 \\
\hline & 1 & 5.885 & 1.388 & 3.138 & 8.632 \\
\hline \multirow{2}{*}{ Video } & 0 & .540 & .106 & .330 & .749 \\
\hline & 1 & 1.164 & .108 & .951 & 1.377 \\
\hline \multirow{2}{*}{ Update } & 0 & .143 & .142 & -.138 & .424 \\
\hline & 1 & 1.098 & .144 & .813 & 1.384 \\
\hline \multirow{2}{*}{ Phone } & 0 & .143 & .050 & .043 & .243 \\
\hline & 1 & .262 & .051 & .161 & .364 \\
\hline \multirow{2}{*}{ Mail } & 0 & .794 & .050 & .694 & .893 \\
\hline & 1 & .820 & .051 & .719 & .921 \\
\hline \multirow{2}{*}{ FB link } & 0 & .825 & .048 & .731 & .920 \\
\hline & 1 & .836 & .048 & .740 & .932 \\
\hline \multirow{2}{*}{ Team info } & 0 & .190 & .036 & .120 & .261 \\
\hline & 1 & 1.000 & .036 & .928 & 1.072 \\
\hline \multirow{2}{*}{ Project info } & 0 & .651 & .050 & .553 & .749 \\
\hline & 1 & .918 & .050 & .818 & 1.018 \\
\hline \multirow{2}{*}{ Risk warning } & 0 & .476 & .061 & .356 & .597 \\
\hline & 1 & .705 & .062 & .583 & .827 \\
\hline \multirow{2}{*}{ No of reward level } & 0 & 3.683 & .252 & 3.183 & 4.182 \\
\hline & 1 & 4.557 & .256 & 4.050 & 5.065 \\
\hline \multirow{2}{*}{ No of backer } & 0 & 18.254 & 20.404 & -22.139 & 58.646 \\
\hline & 1 & 189.000 & 20.736 & 147.951 & 230.049 \\
\hline \multirow{2}{*}{ Goal } & 0 & 760169206.349 & 139649947.372 & 483718187.502 & 1036620225.197 \\
\hline & 1 & 300147196.721 & 141920827.123 & 19200744.593 & 581093648.850 \\
\hline \multirow{2}{*}{ Money raised } & 0 & 199164143.063 & 109879492.816 & -18353287.563 & 416681573.690 \\
\hline & 1 & 614410387.967 & 111666268.394 & 393355856.624 & 835464919.310 \\
\hline
\end{tabular}

Source: Regression results by the authors 
In the Linear Regression Model, the Ordinary Least Squares Estimation method is a popular method used by many researchers around the world, whereby the model considers the term Linear dependence relationship between dependent variable and independent variables in the quantitative form. Variables included in the model are required to be "quantity" variables.

However, in the literature evaluating the success or failure of CF campaigns, with dependent variables being binary variables, it is encouraged to use Logistics Regression Models in testing hypotheses. The dependent variable in this study has only two manifestations of "success" or "failure," so the dependent variable will receive only one in two values: 1 (when CF project is successful) and 0 (when CF project failed). When linear regression model has a dependent variable is a binary variable, the regression model rejectsthe hypothesis of the standard deviation of the error, thus invalidating estimates or statistical tests. Therefore, only variables with coefficient Sig $<0.05$ are statistically significant and are retained in the model.

In addition, Logistic Regression Modelisoften used in forecasting the probability of a dependent variable (CF campaigns succeeding or failing).In this study, this model is appropriate to assess the influence of 14 factors on the probability of project success.Furthermore, the Logistic Regression Model is also used for practical purposes. By using the results from the study, investors can rely on information on independent variables in the model to calculate the probability of success of CF projects. As a result, they can make a sound investment decision, thereby increasing the efficiency of investment.

We measure not only the success or failure of CF campaigns with the Logistic Regression Model but also use a Multiple Regression Model to examine the impact of variables on the percentage of achieving the target capital amount and the number of pledges received through CF campaigns in order to produce more accurate forecasts. We also expect that the results of this model may support projects' owners in determining the probability of reaching the target amount of capital at each stage of a project.Thereby, they can come up with effective strategies in seeking fund through CF.This can also improve the applicability of this study as well as recommendations in following sections.

\section{Research Results and Discussions}

\subsection{Regression Results}

Table 3. Binary Logistics Regression results

\begin{tabular}{|c|c|c|c|c|c|c|c|c|c|}
\hline \multicolumn{10}{|c|}{ Variables in the Equation $^{c}$} \\
\hline & & \multirow[t]{2}{*}{ B } & \multirow[t]{2}{*}{ S.E. } & \multirow[t]{2}{*}{ Wald } & \multirow[t]{2}{*}{$\mathrm{Df}$} & \multirow[t]{2}{*}{ Sig. } & \multirow{2}{*}{$\begin{array}{l}\text { Exp } \\
\text { (B) }\end{array}$} & \multicolumn{2}{|c|}{ 95\% C.I.forEXP(B) } \\
\hline & & & & & & & & Lower & Upper \\
\hline \multirow{4}{*}{ Step $12^{\mathrm{a}}$} & Picture & .160 & .045 & 12.361 & 1 & .000 & 1.173 & 1.073 & 1.282 \\
\hline & Noofbacker & .021 & .006 & 11.045 & 1 & .001 & 1.022 & 1.009 & 1.035 \\
\hline & LnGoal & -.896 & .268 & 11.189 & 1 & .001 & .408 & .242 & .690 \\
\hline & Constant & 14.146 & 4.929 & 8.236 & 1 & .004 & 1391372.34 & & \\
\hline
\end{tabular}

In Binary Logistics Regression model, we used Odd (to predict percentage probability of success of crowdfunding project) as a dependent variable. In this model, after testing hypotheses and eliminating all the factors having sig $<0.05$ ( factor that does not directly impactthe probability of CF project success), wefinally determined three factors :goal, picture (number of pictures) and backer (number of backers)have significant impacts on the success of Vietnamese CF campaigns.

\section{$\operatorname{Ln}($ Odds $)=14.146+0.16 *$ Picture $+0.021 *$ Noofbacker $-0.896 *$ LnGoal $+u_{e}$}

Assuming that originalprobability of project is $10 \%$ and other factors are constant:

Wheneverthe project owner uploads 1 more picture, the probability of success increases $1.53 \%$ over the original probability and reach $11.53 \%$.

$\mathrm{P}_{1}=\frac{P_{0} \cdot \varepsilon^{\beta 1}}{1-P_{0}\left(1-\varepsilon^{\beta 1}\right)}=\frac{0.1 \times 1.173}{1-0.1 \times(1-1.173)}=0.1153=11.53 \%$

$\left(\beta_{1}=0.16, \mathrm{P}_{0}=10 \%\right.$ và $\left.\varepsilon^{\beta_{1}}=1.173\right)$

When one more backer invests in the project, the probability of success increases $0.2 \%$, reaching $10.2 \%$.

$\mathrm{P}_{2}=\frac{P_{0} \varepsilon^{\beta 2}}{1-P_{0}\left(1-\varepsilon^{\beta 2}\right)}=\frac{0.1 \times 1.022}{1-0.1 \times(1-1.022)}=0.102=10.2 \%$ 
$\left(\beta_{2}=0.021, \mathrm{P}_{0}=10 \%\right.$ và $\left.\varepsilon^{\beta_{2}}=1.022\right)$

When the goal (the target amount of money) of the project increases 1\%, the probability of success decreases $5.66 \%$ compared to the original probability and reach $4.34 \%$.

$\mathrm{P}_{3}=\frac{P_{0} \cdot \varepsilon^{\beta 3}}{1-P_{0}\left(1-\varepsilon^{\beta 3}\right)}=\frac{0.1 \times \varepsilon^{0.408}}{1-0.1 \times\left(1-\varepsilon^{0.408}\right)}=0.0434=4.34 \%$

$\left(\beta_{3}=-0.896, \mathrm{P}_{0}=10 \%\right.$ và $\left.\varepsilon^{\beta_{3}}=0.048\right)$

Table 4. Multiple Linear Regression results

\begin{tabular}{|c|c|c|c|c|c|c|c|c|}
\hline \multicolumn{9}{|c|}{ Coefficients $^{\mathrm{a}}$} \\
\hline \multirow{3}{*}{\multicolumn{2}{|c|}{ Model }} & \multirow{2}{*}{\multicolumn{2}{|c|}{$\begin{array}{l}\text { Unstandardized } \\
\text { Coefficients }\end{array}$}} & \multirow{3}{*}{$\begin{array}{l}\text { Standardized } \\
\text { Coefficients } \\
\text { Beta }\end{array}$} & \multirow[t]{3}{*}{$\mathrm{T}$} & \multirow[t]{3}{*}{ Sig. } & \multirow{2}{*}{\multicolumn{2}{|c|}{$\begin{array}{l}95.0 \% \text { Confidence } \\
\text { Interval for B }\end{array}$}} \\
\hline & & & & & & & & \\
\hline & & $\bar{B}$ & Std. Error & & & & $\begin{array}{l}\text { Lower } \\
\text { Bound }\end{array}$ & $\begin{array}{l}\text { Upper } \\
\text { Bound }\end{array}$ \\
\hline \multirow{6}{*}{1} & (Constant) & 1214.224 & 360.471 & & 3.368 & .001 & 500.393 & 1928.054 \\
\hline & Picture & 13.789 & 2.223 & .433 & 6.203 & .000 & 9.387 & 18.192 \\
\hline & Video & 162.052 & 29.126 & .377 & 5.564 & .000 & 104.373 & 219.730 \\
\hline & Mail & 142.981 & 63.718 & .148 & 2.244 & .027 & 16.803 & 269.159 \\
\hline & No of reward level & -39.490 & 12.799 & -.210 & -3.085 & .003 & -64.836 & -14.143 \\
\hline & lnGoal & -67.978 & 17.728 & -.243 & -3.834 & .000 & -103.085 & -32.871 \\
\hline
\end{tabular}

In Multiple Linear Regression model, the dependent variable is the percentage of achieving the goal and is calculated by the amount of investment the project receives divided by the target initial capital amount. In this model, after testing hypotheses and eliminating all the factors having sig $<0.05$, ( factor that does not directly impact the probability of CF project success), we determined that there were five factors including picture (number of pictures), video (number of videos), email, funding level (number of reward levels) and goal having significant impacts on the percentage of achieving funding level.

\section{$\widehat{Y}=0.433 *$ Picture $+0.377 *$ Video $+0.148 *$ Mail- $0.210 *$ No of reward level $-0.243 *$ InGoal}

(In this function, we used standardized coefficients to all independent variables, eliminate constant)

In the multiple regression model, factors affecting the percentage of achieving the project's target capital amount include: number of images, number of videos, target amount of capital, number of investment levels, email of the project founder( arranged in descending order of magnitude). In particular, the number of images, video and email information of the project founderhave a positive impact, while the other two variables have a negative impact on the percentage of achieving the target capital amount of the project. It can be seen that some of the variables appearing in the multiple regression model do not appear in the Logistic regression model. In other words, some variables affect the percentage of achieving the target capital amount but do not affect the success of the project and vice versa.

\subsection{Discussions}

On five CFPs in Vietnam that we collected data from, the requirement that every project has to fulfill if they want their CF campaigns to be announced on the CFP is publishing project's detailed information such as the fund distribution plan, risk information (including commitments), information about project's founder and team (eg. educational background, work experience, etc.), email or phone number of the project ownerand a project's official website (created by the project owner, not including the website on the CFP) if available.

According to our observation, about $90 \%$ of the projects announced on CFP have their own websites and Facebook pages, not justthe project profile on the CFP. However, on foreign CFP such as Kickstarter.com, Indiegogo.com, that requirementis optional to project owners, not mandatory as in Vietnam CFP. This explained the differences between the results of this study in Vietnam and previous studies by Mollick (2014), Koch and Siering (2015), Muller et al. (2013), Colombo et al. (2015). These researchers showed that information influenced the success of the CF campaigns; meanwhile, we discovered that these factors do not have much explanatory meaning for projects in Vietnam. 
Moreover, we found that $90 \%$ of projects had their own Facebook and more than $80 \%$ of them had zero comment on profile pages on CFPs, including both successful and failed projects. Antonento et al. (2014) stated that the number of comment had a positive impact on the success of the campaign; Lin et al. (2013) showed that the project that had Facebook page would have a higher probability of success. However, in this research, we discovered that those factors did not have a direct impact on the probability of success or the percentage of achieving target amount in CF campaigns in Vietnam.

Based on a study by Mollick (2014), we hypothesized that the number of videos positively influenced the success of the CF project. Those projects that Mollick (2014) collected on Kickstarter.com and Indiegogo.com had a large difference between the number of videos of a successful and a failed project in the same category. As a result, video in Mollick's (2014) study has a positive impact on the success of the project (most successful projects have large amounts of video) and vice versa. However, the author's data collection period from 2009 to 2014 is out of date and is different from data collected in this study from January 1, 2015 to March 2017. With the development of information technology, people tend to utilize the use of technology in life, and video is now considered one of the most effective communication tools. According to the data collected on five CFPs in Vietnam, over 85\% of CF projects uploaded videos and most of them had 1 video (both successful and failed projects). Also, the difference in the numbers of videos posted between the successful projects and the failed ones is not large (see details in Table 2).Thus, it is difficult to conclude that video really has an impact on the success of a CF project. The results from the regression model also supportthis opinion. This explains why our results differ from Mollick (2014): with the data collected in Vietnam, we found that the number of videos did not affect the probability of success of a CF campaign.

In addition, when we study and understand CF's in Vietnam, we find that the project's status is usually not updated. Whether the project succeeds or fails, the project owner does not update any other information on the CFP. This leads to the fact that the level of update on the project status is not statistically significant in the Logistic model, nor does it affect the probability of success of a CF project. This result differs from previous studies by Xu et al. (2014) and Giudici et al. (2013), which showed that the level of updating has a positive impact on the success of community mobilization projects.

In terms of duration, we find that both successful and failed projects tend to set the same duration for the CF campaign (usually for a period of 15 to 90 days, but most projects run within 30 days). Successful projects will stop when the durationcomes to an end. However, the failed projects also have the same duration as the successful ones.

There may be various reasons to explain this issue. Firstly, in Vietnam, most project owners tend to set a funding duration for their projects as long as previous successful projects. Therefore, it is impossible to avoid large numbers of projects with the same number of days of implementation (though the final results are different). Secondly, projects on Kickstarter.com and Indiegogo.com (two CFPs used by the majority of the world's researchers) tend to end the project by the expiry date when they notice that the amount of raised capital exceeds $100 \%$ of the target capital amount. However, successful projects in Vietnam usually run to the last day with the desire to raise the largest amount of capital as well as to increase opportunity to attract new investors, meanwhile, failed projects also run until the last day, hoping that miracle would happen. Therefore, it is difficult to see the difference in the duration of the successful project compared to the failed project as well as the impact that duration has on the probability of success of CF campaigns in Vietnam. While the results of Mollick (2014), Ahlers et al. (2015), Leboey and Schwienbacher (2015), Muller et al. (2013) showed that the project implement duration negatively impacted the probability of success of projects, it is difficult to assess the impact of duration on the success of CF projects in Vietnam. This is also the reason why this variable is not statistically significant in the model.

One of the key benefits that CFP executives use to attract project owners to conduct CF campaigns on their platforms is to allow project owners to select different levels of funding and rewards for their own projects. There are websites allowing project owners to set different levels of capital contribution, while others also set funding and reward levels for each project. This led to differences in the number of reward levels at various CFPs and projects, and also shows the reason why the amount of capital contribution was not significant in the logistic regression model.

In this study, we assumed that the target capital volume had a negative impact on the success of a community mobilization project, with a beta coefficient of -0.896 and a Sig value of $<0.05$. The results show that target amount (the goal of CF campaign) is indeed statistically significant and has a negative impact on the hypothesis. This result is in line with previous studies by Leboey and Schwienbacher (2015), Mollick (2014). According to this result, the smaller the projected target capital amount, the easier it is to attract people to invest (with a small amount of money, investors may be willing to make investments without considering for too long) and the sooner founder reaches his goal. 
According to our hypothesis, the number of uploaded images will have a positive impact on the probability of success of the project. This is due to the fact that people tend to memorize images better than text. With the beta coefficient of 0.16 andSig value of $<0.05$, we found that the number of images was statistically significant and positively influenced the probability of success of CF projects. This result confirms the hypothesis is true and is also in line with the previous research by Koch and Siering (2015).

In the previous studies, Loboey and Schwienbacher (2015), Ahlers et al. (2015) demonstrated that the greater the number of backers, the greater the amount of capital would be raised and the more likely that the project would succeed. Inheriting the results of these above researchers, we also set out the same hypothesis. The result of the logistic regression model on the number of funders shows that the beta coefficient $=0.021$, the Sig value $<0.05$, which means the number of backers indeed has a positive effect on the probability of success of CF projects in Vietnam. However, the number of backer does not impact the percentage of achieving the target amount.The reason for this issue might be because the total amount of money a project can raise through a CF campaign depends not only on the number of backers but also the amount of fund each backers contribute to the project. For instance, a CF campaign in which the number of backers is small but each backerscontribute a large amount of money for the project will be more likely to succeed than another project in which there is a greater number of backers but each backers contribute a smaller amount of fund.

It is essential to emphasized that successful and failed projects have different percentages of achieving the target amount. The factors influencing the percentage of achieving the target capital amount are unlikely to have a direct impact on the success of CF projects (successful projects with a target capital of greater than or equal to 100\%). In addition, the dependent variables of the two logistic models and the multiple regression model were identified and measured in different ways (as they serve two different purposes), therefore, the effects of the independent variables on them will not be the same.

\subsection{Crowdfunding in Vietnam - Prospects and Challenges}

Though it has been used for years in funding creative projects, CF is still in its infancy in Vietnamese market. In order to gain a comprehensive view of applying CF in funding for Vietnamese startups, it is vital to understand the context of crowdfunding. In this study, we use PEST analysis to examine the context of CF application in Vietnam. Based on PEST analysis, we also define prospects and challenges of which all partiesshould be aware before they take part in a crowdfunding campaign. 
Table 5. Crowdfunding in Vietnam - prospects and challenges

\begin{tabular}{ll}
\hline Political & Prospects \\
Factors & $\checkmark$ Vietnam has a stable political climate, which \\
& investment. \\
& $\checkmark \quad$ The government is implementing a variety of \\
policies to support start-up businesses in raising \\
capital. \\
$\checkmark \quad$ Authorities are establishing and finalizing the \\
legal framework for CF in Vietnam. \\
$\checkmark \checkmark$ The economy is growing with great potential \\
and prospects. Growth is concentrated in the private \\
sector and this is also a region has great demand for \\
capital as well as good capital absorption. \\
$\checkmark \quad$ Business environment in Vietnam is \\
considered to be more attractive in 2017 , this would \\
encourage enterprises and investor to enter \\
Vietnamese market. \\
$\checkmark \quad$ The policy of reducing Corporate Income Tax \\
facilitates the operations of enterprises. \\
$\checkmark \quad$ Per capita income in Vietnam is gradually \\
increasing over years. In the long term, it is \\
predicted that there will be an upward trend in the \\
number of middle-class population in Vietnam - this \\
prediction also shows the capability of investing of \\
general population.
\end{tabular}

Social

Factors

Technological Factors

\section{Challenges}

- $\quad$ The law drafts on CF are simple and have not yet been promulgated. There has been no specific regulation and guideline for implementation of CF in Vietnam yet. This would lead to difficulties in raising capital through CF campaigns.

- $\quad$ The process of paying tax is complicated and time-consuming.

- Inflation in 2017 also has the potential to increase, this might lead to a reduction in the amount of investment in society.

- The general notion of failure in Vietnam and the fear of criticism creates a barrier for project owners to participate in CF.

- $\quad$ Funders are reluctant to invest in ventures and people they do not have a personal relationship.

- $\quad$ There is a lack of awareness of CF among people in Vietnam, includes project initiatives and potential investors.

- Consumers in Vietnam have a habit of direct shopping and lack trust with information and online transactions.

- $\quad$ The issue of network security is of concerned. platform in Vietnam are increasingly improving and enhancing the adaptability to online activities.

$\checkmark \quad$ The number of Internet users in Vietnam accounts for more than half of the total population and is continuously increasing.

$\checkmark \quad$ Online payment services and online transactions in Vietnam are being developed and becoming more and more popular. 
From the above analysis, it can be seen that the application conditions of CF for Vietnamese startups are being established and improved, creating great potential for the development of this novel funding channel in Vietnam. However, the most significant challenge facing this financing model is the willingness of the funders, which is constrained by cultural and social factors and will take a great amount of time to change.

\section{Recommendations and Conclusions}

\subsection{Recommendations}

From the research results, we proposed a number of recommendations for all partiestaking part in CF ecosystem, in order to improve the effectiveness of CF process as well as the success of CF campaigns of Vietnamese startups.

Businesses and startups seeking capital: the project initiator should set a realistic goal with an appropriate target capital amount for his venture, which is suitable for each phase of the project. It is also necessary for the project founders to distribute the amount of money clearly and logically in the business plan. In order to enhance the effectiveness of CF campaigns, project owners should increase the use of images and videos in promoting and updating the implementation of the project. In that way they can enhance interaction between them and large numbers of crowdfunders, potential investors, project supporters, therefore they will be able to strengthen the social network ties which are found to be important in crowdfunding (Mollick, 2014). Further, it is also vital to utilize the wisdom of the crowd by encouraging crowdfunders to contribute their ideas in developing the projects' products or services.

Crowdfunders: The first and most significant step for crowdfunders to participate efficiently in crowdfunding campaigns is enhancing their understanding of crowdfunding and how it works. In addition, it is vital for funders to learn about project and project owner before making any investment decision to protect themselves against investment risk (Bradford, 2012). At the same time, funders should actively engage in the crowdfunding campaign by contributing their ideas to develop the project's products or services and introducing the project to their friends to make the venture more and more popular with the crowd.

Crowdfunding Platforms: In addition to connecting investors to projects, CFPs might need to set up professional committees and develop consulting services to assist startup founders in raising capital and funders in making investment decisions in order to increase the efficiency of CF campaigns.

Authorities and Policymakers: It is essential to establish a framework, set out regulations implementation guides for CF in Vietnam. In the first step of applying CF in Vietnam, authorities might take the responsibility for being the lead agency facilitating CF process, building trust and encouraging the use of CF in raising capital for startups. Further, with the aim of utilizing the social capital efficiently, authorities should pay more attention to enhancing capacity and competitiveness of startups as well as improving the quality of ventures so as to achieve the sustainable development in the long term.

\subsection{Conclusions}

$\mathrm{CF}$ is still a novel funding channel for startups in Vietnam, therefore, it needs to be clarified and studied in various aspects before being appliedas an official financing method. With the application of Binary Logistics Regression and Multiple Linear Regression, we have explored and evaluated factors influencing the probability of success of a CF campaign in Vietnam in order to assist project owners and potential funders to have a clearer view on the prospect of ventures, thereby making informed decisions. In addition, PEST analysis allows revealing the context of CF in Vietnam and shed lights on prospects as well as challenges facing this novel financing method.

This exploratorystudy of CF has provided avenues for future research. The topic of factors influencing the success of $\mathrm{CF}$ campaigns of startups in Vietnam needs to be analyzed deeper with various factors, which are not shown on the CFP, such as the network of project founders. In general, before applying CF as an official financing source in Vietnam, there is a variety of questions on different aspects of CF, such as legal framework or the engagement of socialin CF campaigns, need to be considered and addressed with further researches.

The research has some limitation because the lack of information on the startup and crowdfunding in Vietnam. Up to now, there have not been an official data colllections or comprehensive information published. It led to difficulties for researchers in Vietnam to collect data and information. Then, our findings and analyis only based on our collection from 124 projects' profiles on CFPs and is still available to access until the research period. These could be a representatation for the whole startup population in Vietnam but it woud be better if more observations included. 


\section{References}

Antonenko, P.D., Lee, B.R. \& Kleinheksel, A.J. (2014). Trends in the crowdfunding of educational technology startups. TECHTRENDS TECH TRENDS, 58-36.

Arolas, E. E., \& 'n-de-Guevara, F. G.-L. (2013). Towards an integrated crowdsourcing definition. Journal of Information Science, 189-200.

Agrawal, A. K., Catalini, C., \& Goldfarb, A. (2011). The Geography of Crowdfunding. Cambridge, MA: NATIONAL BUREAU OF ECONOMIC RESEARCH. https://doi.org/10.3386/w16820

Ahlers, G. K., Cumming, D., Günther, C., \& Schweizer, D. (2015). Signaling in Equity Crowdfunding. Entrepreneurship Theory and Practice, 955-980. https://doi.org/10.1111/etap.12157

Belleflamme, P., Lambert, T., \& Schwienbacher, A. (2010). Crowdfunding: An Industrial Organization Perspective. Prepared for the workshop Digital Business Models: Understanding Strategies', held in Paris on June. 2010.

Belleflamme, P., Lambert, T., \& Schwienbacher, A. (2013). Crowdfunding: Tapping the right crowd. Journal of Business Venturing.

Bradford, C. S. (2012). Crowdfunding and the Federal Securities Laws.

Buysere, K. D., Gajda, O., Kleverlaan, R., \& Marom, D. (2012). A Framework for European Crowdfunding. European Crowdfunding Network.

Chen, X.-P., Yao, X., \& Kotha, S. (2009). Entrepreneur passion and preparedness in business plan presentations: a persuasion analysis of venture capitalists' funding decisions. Academy of Management Journal, 52(1), 199-214.

Cheung, C. M., Lee, M. K. \& N. Rabjohn. (2008). The impact of electronic word - of - mouth. Inter- net Research 18(3), 229-247. https://doi.org/10.1108/10662240810883290

Colombo, M. G., Franzoni, C. \& Rossi-Lamastra, C. (2015). Internal Social Capital and the Attraction of Early Contributions in Crowdfunding. Entrepreneurship Theory and Practice, 39, 75-100. https://doi.org/10.1111/etap.12118

Cordovaa, A., Dolcib, J., \& Gianfrate, G. (2015). The determinants of crowdfunding success: evidence from technology projects. 3rd International Conference on Leadership, Technology and Innovation Management (pp. 115-124). Procedia-Social and Behavioral Sciences. https://doi.org/10.1016/j.sbspro.2015.04.872

Drabløs, C. (2015). What influences crowdfunding campaign success (Master's thesis, Universitetet i Agder; University of Agder).

Gerber, E. M., Hui, J. S., \& Kuo, P.-Y. (2012). Crowdfunding: Why People Are Motivated to Post and Fund Projects on Crowdfunding Platforms. Proceedings of the International Workshop on Design, Influence, and Social Technologies: Techniques, Impacts and Ethics, (p. 11).

Hagedorn, A., \& Pinkwart, A. (2015). The financing process of equity-based crowdfunding: An empirical analysis. Crowdfunding in Europe. Springer International Publishing, 71-85.

Hemer, J. (2011). A Snapshot on Crowdfunding. Karlsruhe, Germany: Fraunhofer Institute for Systems and Innovation Research ISI.

HSBC Bank. 2017. Asian Connected. Sydney: Export Council of Australia.

Koch, Jascha-Alexander, Siering, Michael. (2015). Crowdfunding success factors: The characteristics of successfully funded projects on crowdfunding platform. Working paper.

infoDev. (2013). Crowdfunding's Potential for the Developing World. Washington, DC: Finance and Private Sector Development Department, World Bank.

Jegelevičiūtè, S., \& Valančienè, L. (2015). Comparative analysis of the ways crowdfunding is promoted. 20th International Scientific Conference Economics and Management - 2015 (ICEM-2015) (pp. 268-274). Procedia Social and Behavioral Sciences. https://doi.org/10.1016/j.sbspro.2015.11.536

Kraus, S., Richter, C., Brem, A., Cheng, C.-F., \& Chang, M.-L. (2016). Strategies for reward-based crowdfunding campaigns. Journal of Innovation \& Knowledge, 13-23. https://doi.org/10.1016/j.jik.2016.01.010

Leboeuf, G., Schwienbacher, A., Cumming, D. (2015). Crowdfunding Models: Keep-It-All vs. All-Or-Nothing. Working paper. 
Lin, L. (2017). Managing the Risks of Equity Crowdfunding: Lessons from China. Journal of Corporate Law Studies. https://doi.org/10.1080/14735970.2017.1296217

Lin, M., Prabhala, N. R., \& Viswanathan, S. (2014). Judging borrowers by the company they keep: friendship networks and information asymmetry in online peer-to-peer lending. Management Science, 59(1), 17-35.

Mollick, E. (2014). The dynamics of crowdfunding: An exploratory study. Journal of Business Venturing, 1-16. https://doi.org/10.1016/j.jbusvent.2013.06.005

Pazowski, P., \& Czudec, W. (2014). Economic prospects and conditions of crowdfunding. Human capital without borders. International conference management knowledge and learning, (pp. 1079-1088). Portoroz, Slovenia.

PwC. (2016). The long view: how will the global economic order change by 2050 ?

Rossi, M. (2014). The New Ways to Raise Capital: An Exploratory Study of Crowdfunding. International Journal of Financial Research. https://doi.org/10.5430/ijfr.v5n2p8

Röthler, D., \& Wenzlaff, K. (2011). Crowdfunding Schemes in Europe. European Expert Network On Culture (EENC).

Sigar, K. (2012). Fret no more: inapplicability of crowdfunding concerns in the internet age and the JOBS Act's safeguards. Administrative Law Review (pp. 473-506). American Bar Association.

Valanciene, L., \& Jegeleviciute, S. (2013). Valuation of crowdfunding: benefits and drawbacks. Economics and Management, 39-48.

Valančienè, L., \& Jegelevičiūtè, S. (2014). Crowdfunding for creating value: stakeholder approach. 19th International Scientific Conference; Economics and Management 2014. Riga, Latvia: Procedia - Social and Behavioral Sciences.

General Statistic. (2017). Overiview of economic and social issues in $1^{\text {st }}$ Quarter 2017

VEPR. (2017). Vietnam economics Report, $1^{\text {st }}$ Quarter 2017.

Wroldsen, J. S. (2012). The Social Network and the Crowdfund Act: Zuckerberg, Saverin, and Venture Capitalists' Dilution of the Crowd. VANDERBILT J. OF ENT. AND TECH. LAW. 